\title{
Sexuality of the disabled often overlooked
}

$\mathrm{W}$

hile few caregivers would think twice about assisting a person with disabilities in the bathroom, many feel squeamish about advising or assisting that same person in the bedroom.

The sexuality of people with disabilities, many of whom require varying degrees of assistance to lead fulfilling sex lives, continues to be overlooked, avoided or even dismissed as a component of holistic care because of a longstanding stigma that shrouds disability and sex. A dearth of resources, training and infrastructure to guide caregivers and patients in addressing sexual needs contributes to the problem.

Embryonic efforts are now being made to develop manuals and other tools that might guide clinicians in helping disabled patients learn how to satisfy their sexual needs. To that end, the Vancouver Coastal Health Authority has released Supporting Sexual Health and Intimacy in Care Facilities guidelines, which state that care facilities have an "ethical and legal obligation to recognize, respect and support clients' sexual lives" (www.vch.ca/media/Facilities Licensing_SupportingSexualHealth andIntimacyinCareFacilities2.pdf).

As well, the United States Consortium for Spinal Cord Medicine in 2010 released Sexuality and Reproductive Health in Adults with Spinal Cord Injury, a clinical practice guideline that likewise instructs health care professionals to deal with the topic of sexuality openly and proactively (www.pva .org/site/News2?page=NewsArticle\&id $=14991$ ).

In Ontario, Cory Silverberg, coauthor of The Ultimate Guide to Sex and Disability, and Fran Odette, program manager at Springtide Resources, started the Sexuality and Access Project to improve the sexual health of people with disabilities. The first phase of the project began in 2009 with an online survey distributed to people with disabilities and attendants throughout Ontario to find out what

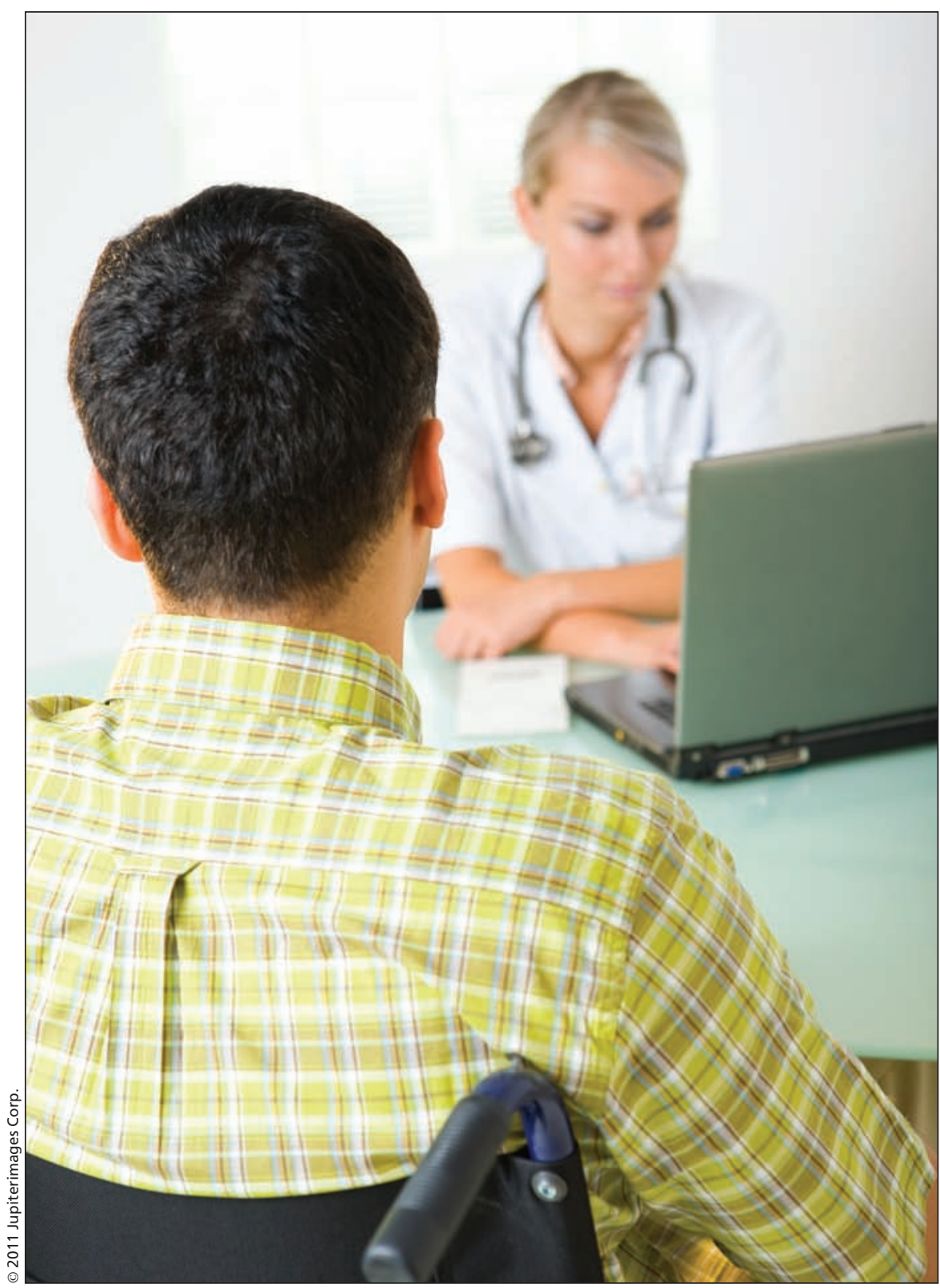

Doctors and other health care providers often have problems discussing sex with disabled patients, experts on disability say.

their experiences were with requesting or providing sexual support. The data collected from the survey is now helping to create a training manual for attendants.

Such tools might eventually help clinicians overcome their discomfort in discussing the subject with patients, says Zoe Vourantoni, a sexologist at the Cen- tre de réadaptation Lucie-Bruneau in Montréal, Quebec. "I think [clinicians] feel very inappropriate or out of place even though they know that the sexuality of the person right in front of them has been modified or affected - but there's just something socially wrong about imposing yourself on somebody's intimacy," she says. 
But regaining sexual function is a high priority for people who've suffered spinal cord injuries ( $J$ Neurotrauma 2004; 21: 1371-83).

"Most guys are thinking about it almost instantly," says Brad Jacobsen, 41, a quadriplegic peer associate with the British Columbia Paraplegic Association who suffered a spinal cord injury at the age of 24 after diving into a glacier river.

Typically, care providers for people with disabilities are divided into two categories: the clinicians who help with rehabilitation and other services away from home, and attendants who help with daily tasks like movement, washing and meal preparation. Both often have the same problems discussing sex with their patients.

But that works both ways. Patients are often just as uncomfortable.

In order to get into a position where they can either masturbate or have sex with a partner, some people require an attendant's help. But that can be "a very touchy, kind of thin line subject," Jacobsen says.

Others, though, seem to have few reservations.

"You know, your staff are trained to look after bowel, bladder, wounds, everything else, right, so it's just basically one other thing," says 34-year-old Brad Zdanivsky, a quadriplegic and an information technology consultant from
Vancouver, BC, who uses a vibrostimulation device to achieve an orgasm and needs an attendant to help position him, clean up and be available (in an adjoining room), should he experience a spike in blood pressure.

Once someone's been through rehab, privacy is less of an issue, Zdanivsky says. "If you've been in the hospital and you've been picked and prodded by doctors and students, you're pretty used to just talking about that stuff."

That sort of candour is all but impossible for teenagers with a disability, because their attendants are usually their parents, says Dr. Miriam Kaufman, a pediatrician at SickKids Hospital in Toronto and coauthor of The Ultimate Guide to Sex and Disability. "Most young people are not going to feel comfortable asking their parents to do something that would help them have sex and most parents would not agree to that because most parents don't think that their kids should be having sex."

Attendants, such as Sudbury, Ontario's Paul McDowell, suggest that the key is for the attendant to feel comfortable.

"Because I'm relaxed, I guess it makes them relaxed," McDowell says.

Clinicians and attendants need to be more comfortable with sex in general, says Silverberg, founder of the Come As You Are sex store in Toronto. "I think their discomfort - it gets labelled as being about sex and disability when in fact I would say the majority of it is discomfort about sex. The first task is to get care workers - first of all, any kind of professional - to acknowledge that sexuality is important, period."

"Most people still think of sexuality as something of a luxury," he adds.

Jacobsen recommends education sessions about sexual health for people with disabilities, with a chair to facilitate the discussion.

Meanwhile, the Disabilities Health Research Network says that an array of devices can help people have sex (www .dhrn.ca/files/sexualhealthmanual_low res_2010_0208.pdf). And sometimes, all that needs to be done is letting a person know about the help that is available, and then leaving them to ask for it, when they're ready.

During rehabilitation, some people aren't initially prepared to discuss sexuality, says Dr. Andrei Krassioukov, the director of the Autonomic Research Unit in the Spinal Cord Program at the GF Strong Rehabilitation Centre in Vancouver. But if they are informed about available assistance "in a nonintrusive way," and periodically reminded of that, they often warm to discussing the notion. - William Burr, Ottawa, Ont.

CMAJ 2011. DOI:10.1503/cmaj.109-3813 